\title{
Breeding Trait Priorities of the Cranberry Industry in the United States and Canada
}

\author{
R. Karina Gallardo \\ School of Economic Sciences, Puyallup Research and Extension Center, \\ Washington State University, 2606 W. Pioneer Street, Puyallup, WA 98371 \\ Parichat Klingthong \\ Fiscal Policy Office, Ministry of Finance, Khet Pahya Thai, Krung Thep \\ Maha Nakhon, Thailand, 10400
}

Qi Zhang

School of Economic Sciences, Washington State University, P.O. Box 646210, Pullman, WA 99164

James Polashock

USDA-ARS, 125A Lake Oswego Road, Chatsworth, NJ 08019

Amaya Atucha

Department of Horticulture, University of Wisconsin-Madison, 1575 Linden Drive, Madison, WI 53706

\section{Juan Zalapa}

USDA-ARS, Vegetable Crops Breeding Unit, Department of Horticulture, University of Wisconsin-Madison, 1575 Linden Drive, Madison, WI 53706

Cesar Rodriguez-Saona and Nicholi Vorsa

P. E. Marucci Blueberry and Cranberry Research and Extension Center, Rutgers University, 125A Lake Oswego Road, Chatsworth, NJ 08019

\section{Massimo Iorizzo ${ }^{1}$}

Plants for Human Health Institute and Department of Horticultural Science, North Carolina State University, 600 Laureate Way, Kannapolis, NC 28081

Additional index words. cranberry breeding, stakeholder's preferences survey, cranberry cultivar, Vaccinium macrocarpon

\begin{abstract}
Informed assessment of priority genetic traits in plant breeding programs is important to improve the efficiency of developing cultivars suited to current climate and industry needs. The efficiency of genetic improvement is critical for perennial crops such as cranberries, as they usually involve more resources, time, and funding compared with other crops. This study investigated the relative importance of cranberry producers' preferences for breeding traits related to fruit quality, productivity, plant physiology, and resistance to biotic and abiotic stresses. Industry responses revealed that fruit characteristics affecting fruit quality, including firmness, fruit size and anthocyanin content, and resistance to fruit rot, were the most desired traits in new cranberry cultivar release. These traits have the potential to increase the quality standards needed to process high-value sweetened dried cranberry products, positively affecting price premiums received by producers, which is critical for the economic viability of the cranberry industry. Our findings will be useful to breeders and allied scientists seeking to develop an advanced DNA-based selection strategy that would impact the global cranberry industry.
\end{abstract}

North America, led by the United States, is the world's largest producer of cranberries (Vaccinium macrocarpon Ait.). In 2016, the United States produced $68 \%(419,606 \mathrm{t})$ of the global cranberry production, followed by Canada with 29\% (179,574 t) (CMC, 2016; FAOSTAT, 2016). In 2017, the states with the highest cranberry production in the United States were Wisconsin $(240,538$ t), Massachusetts $(95,370$ t), New Jersey (26,090 t), Oregon $(17,211 \mathrm{t})$ and Washington (7233 t) (CMC,
2017). In Canada, British Columbia and Quebec (CMC, 2017) are the provinces with the highest cranberry production. The dissemination of health benefit research findings derived from cranberry consumption (Forney and Kalt, 2011; Huang et al., 2016; Song et al., 2016) has led to an increase in consumption and production in the United States. Cranberry production in the United States increased $46 \%$ from 2004 to 2016 (USDA NASS, 2017a), positively impacting the economy of the production regions (Alston et al., 2014). From 2009 to 2012, Alston et al. (2014) estimated that the processing cranberry industry was responsible for $\$ 3.55$ billion annually in value-added output in the United States and \$411 million in Canada. Employment was positively affected, as 11,600 jobs were created in the United States and 2700 in Canada. In the United States, over $95 \%$ of the cranberry production is destined for processing, whereas only $3 \%$ to $5 \%$ is used for fresh fruit consumption (average data for 2014 to 2016, USDA NASS, 2017b). In the last 25 to 30 years, cranberry products have gone through continuous diversification. Until 2010, cranberry juice cocktail products constituted the largest market share. However, after 2010, sweetened-dried-cranberries (SDC) became the most popular processing product, being used as a component of breakfast cereals, energy bars, and baked goods, among others (Vorsa and Johnson-Cicalese, 2012). Despite the production increase, the United States cranberry industry is facing multiple challenges that are affecting stakeholders' profitability (FCE, 2015).

Cranberry production increased substantially during the last decade primarily due to improved management practices and the adoption of new cultivars. Also during that time, the cranberry industry shifted from primarily processing fruit for juice production to a duel production stream of juice and SDCs (Nolte, 2015; Serres, 2017). The latter product requires specific quality characteristics of individual fruit to maximize the end product quality and production efficiency. About $20 \%$ to $30 \%$ of the annual cranberry production is diverted from SDC processing lines to the lower-value single-stream juice production lines, because those berries do not meet the quality specifications for SDCs (R. Serres, personal communication). As a result, the overall price of cranberry production has decreased (USDA-ERS, 2017), compromising producers' profitability. Another challenge is the new regulation requiring labeling if the processed cranberry product has added sugar (U.S. FDA, 2016). Raw cranberries are especially tart due to their low sugar content and high acidity. For this reason, cranberry products have sugars added to make them palatable. The risk with the new FDA Nutrition Facts Label regulation is that consumers will avoid nutrient dense foods, such as cranberry, that have added sugars to improve palatability (U.S. FDA, 2018). Other production challenges, include increasing disease and insect pressures with concurrent restrictions on certain pest control products, as well as climate change (Vorsa and Johnson-Cicalese, 2012). Development of new cranberry cultivars exhibiting the fruit-quality standards demanded by the SDC industry, while overcoming other production challenges, will enhance the growth of the cranberry industry in North America and worldwide. It is believed that the release of new cultivars with increased and consistent yields and high anthocyanin content were responsible for the increase in cranberry demand (Vorsa and Johnson-Cicalese, 2012). 
Traditional cranberry breeding ( $V$. macrocarpon Ait., $2 n=2 x=24$ ) is a long process, taking 10 to 30 years from the original cross to cultivar release. This process often results in the improvement of only a few traits (Vorsa and Johnson-Cicalese, 2012). The recent expansion of genomic resources for cranberry makes the application of marker-assisted selection (MAS) a feasible and cost-effective breeding method for this crop (Covarrubias-Pazaran et al., 2016; Daverdin et al., 2017; Schlautman et al., 2017). MAS is a critical complement for cranberry breeding, due to lengthy selection cycles for cultivar development. In the last 10 years, MAS has become a cost-effective strategy for crop improvement programs by increasing selection efficiency, thus shortening cultivar development time (Yang et al., 2015). However, the application of MAS technologies requires extensive training, knowledge, and significant initial investment to generate genomic resources. For this reason, breeding efforts should focus on traits of maximum value (Alpuerto et al., 2009; Luby and Shaw, 2001). Determining breeding priorities is challenging, since trait relevance often varies across the supply chain. As a result, only a few studies have investigated trait priorities for plant breeding programs (Gallardo et al., 2012, 2018; Yue et al., 2013).

To date, no study has been conducted to determine cranberry stakeholder preferences for plant and fruit quality traits. Grower associations and commodity commissions at the regional level in the United States and Canada define research priorities providing useful information on producer's priorities relevant to superior cultivars. However, not all priorities are necessarily focused on problems that can be addressed through breeding. Past and current breeding efforts in cranberries have prioritized 1) increased and consistent yields; 2) increased vine vegetative vigor during establishment years; 3) increased fruit anthocyanin content; and 4) disease resistance. However, there is a growing need to focus on other traits, such as tolerance to pest and abiotic stress, as well as to effectively pyramid multiple traits, as they become relevant to the success of the industry (Vorsa and Johnson-Cicalese, 2012).

\footnotetext{
Received for publication 15 May 2018. Accepted for publication 13 Aug. 2018.

The funding for this study was provided by the USDA Specialty Crop Research Initiative, NIFA Award Number 2016-51181-25401. M.I. was supported by the United States Department of Agriculture National Institute of Food and Agriculture, Hatch project 1008691.

We gratefully acknowledge the support and assistance of Parichat Klingthong, Rebecca Harbut, Megan Bame, Hamed Bostan, Yunyang Zhao, Kim Hummer and Penelope Perkins-Veazie. We acknowledge the Cape Cod Cranberry Growers Association, New Jersey Blueberry and Cranberry Research Council, Ocean Spray Cranberry, Wisconsin State Cranberry Growers Association and The Cranberry Institute for supporting the planning grant. ${ }^{1}$ Corresponding author. E-mail: miorizz@ncsu.edu. This is an open access article distributed under the CC BY-NC-ND license (http://creativecommons. org/licenses/by-nc-nd/4.0/).
}

The objectives of this study were to identify and prioritize cranberry producers' preferences for fruit and plant quality traits. In addition, the most important traits are discussed to capture the status of scientific knowledge based on published phenotyping and genetic studies in cranberry. This information will provide guidance for the choice of goals/objectives for breeders and allied scientists to facilitate the selection of improved cranberry cultivars as perceived by producers.

\section{Methods}

\section{Survey design}

Research priorities from state/provincial cranberry commodity groups (Massachusetts, Wisconsin, and British Columbia, Canada), and from two national or regional research organizations (USDA-ARS $\mathrm{Na}$ tional Clonal Germplasm Repository Small Fruit Crop Germplasm Committee and the Cranberry Institute) were extracted from recent grant proposal requests and research priority recommendations. These were grouped according to the production-related needs (e.g., pest and disease related traits) to identify clusters of fruit and plant traits that could directly or indirectly affect cranberry industry profitability. Hereafter, the term "cranberry industry" refers to nurseries, producers, packers, processors, breeders, and nonbreeder researchers. Five trait clusters were derived from this list, including 1) fruit quality, 2) disease resistance, 3) arthropod pest resistance (note that the survey used "insect pest resistance" to refer to arthropod pest resistance, which we use hereafter, because some pests are not true insects), 4) plant stress tolerance, and 5) other plant traits. Each cluster of traits included an "other trait" option in case we missed an important trait in the list of traits presented to the respondents. The survey form, which was approved by the Institutional Review Board, Washington State University IRB $\# 15708$, is available at the Planning Project webpage https://pgnglab.plantsforhumanhealth. ncsu.edu/vaccinium-project/survey/.

Firmness, fruit size, anthocyanin content, shelf life, flavor, and sweetness were included in the fruit quality cluster. The disease resistant traits included bitter rot (Colletotrichum spp.), cottonball (Monilinia oxycocci), cranberry canker (auxin-producing bacteria), early rot and phyllosticta leaf drop (both caused by Phyllosticta vaccinii), fairy ring (Helicobasidium sp.), false blossom (16SrIII group phytoplasma), field fruit rot (various fungal species), leaf spots (various fungal species), nematodes (various species), phytophthora (Phytophthora spp.), storage rots (various fungal species), upright dieback (Phomopsis vaccinii), and other diseases. The arthropod pest traits included were blackheaded fireworm (Rhopobota naevana), blunt-nosed leafhoppers (Limotettix vaccinii), cranberry blossom worm (Epiglaea apiata), cranberry fruitworm (Acrobasis vaccinii), cranberry weevil (Anthonomus musculus), cranberry tipworm (Dasineura oxycoccana), red-headed flea beetle (Systena frontalis), cranberry gir- dler (Chrysoteuchia topiaria), grubs (Phyllophaga spp. and oriental beetle-Anomala orientalis), root weevils (black vine weevil-Otiorhynchus sulcatus; and strawberry root weevil-O. ovatus), scale insects (multiple species including cranberry scaleAspidaspis oxycoccus; Dearness scale-Rhizaspidiotes dearnessi; Lecanium scale-Lecanium corni; and Putnam scale-Diaspidiotus ancylus), Sparganothis fruitworm (Sparganothis sulfureana), spotted fireworm (Choristoneura parallela), thrips (unknown spp.), cranberry toad bugs (Phylloscelis atra), and other arthropod pests. The plant stress tolerance traits included drought resistance, fall and spring frost tolerance, heat stress, yellow vine, midwinter cold hardiness, and other plant stress. The other plant traits included were early harvest, flowering/fruit set, yield, runnering (branching) habit, and others.

The survey included questions asking participants to rank the relative importance of individual traits in each of the five trait clusters (questions 1-5) to obtain a commercially successful cranberry cultivar. Next, participants were asked to rank the importance of the five trait clusters (question 6). In each cluster, we asked respondents to rank the first, second, third, etc. most important and the first, second, third, etc. least important traits for a successful cultivar. The ordering number requested (first, second, third, etc.) varied depending on the number of traits included in each cluster. For example, the fruit quality cluster included seven traits, hence ranking was requested for the two most and the two least important fruit quality traits. The disease resistance cluster included 13 traits, thus we requested respondents to rank the four most and the four least important disease resistance traits.

Other questions in the survey asked for socio-demographic characteristics of the decision makers and the cranberry operation, including the respondent's role in the supply chain (e.g., producer, nursery operator, packer, processor, breeder, and nonbreeder scientist); the size of the respondent's cranberry operation expressed in acres of the cultivated area; the number of years the respondent had been involved in the decision-making process of the operation; a list of cranberry cultivars representing the largest cultivated area in the respondent's operation; whether new cultivar(s) had been planted during the last 5 years; the name of the cultivar(s) planted during the last 5 years; and the name of the state in which the largest cultivated area of the operation was located.

\section{Data collection}

The cranberry industry survey was conducted at grower meetings in two U.S. states, New Jersey and Wisconsin, and one Canadian province, British Columbia, between January and April 2017. The names and locations of the meetings were 1) the Wisconsin Cranberry School, Wisconsin, Jan. 2017; 2) the American Cranberry Grower Association Winter Meeting, New Jersey, Jan. 2017; and 3) BC 
Cranberry Conference, British Columbia, Apr. 2017.

At each meeting, a scientist or extension educator associated with this study presented the content and the objective of the survey in a Power Point (version 2013; Microsoft, Redmond, WA) presentation while the audience responded to a paper-based survey.

\section{Data analysis}

To quantify the importance of traits and industry related variables across regions, we analyzed the data using an ordered probit model given that the dependent variable, the ranking of traits, was discrete and ordinal as described by Gallardo et al. (2018). Each breeding trait described in the previous section was included in the econometric model as a variable, and was assigned a number according to each respondent's ranking. For example, for the trait cluster fruit qualityincluding six fruit quality traits-the trait identified as most important by a respondent was assigned a " 1 ," the second most important was assigned a " 2 ," the second least important trait was assigned a " 5 ," and the least important trait was assigned a " 6 ." Traits not identified by the respondent as being among the most or the least important in the trait cluster fruit quality were considered middle choices and were assigned the median value, in this case 3 . This method has been used in previous research to elicit the relative level of importance of product attributes (Davis and Gillespie, 2004; Gallardo et al., 2018; Greene and Hensher, 2008; Yue et al., 2013).

The ranking of traits was assumed to depend on the underlying utility or measurement of preference derived from the presence of each trait in the cranberry cultivar. The respondents ranked the traits based on a perception of which ones would provide them with the most benefits. Here, the benefits are the present value of all the elements that the respondent considers when ranking the traits according to their preferences, which is the same role represented in the utility. This approach follows Lancaster's theory of consumer behavior that states that utility is not derived from a good, but rather from the attribute composition of that good (Lancaster, 1966). In this instance, suppose $U_{i t}$ is the utility that respondent $i$ derives from trait $t$ and $U_{i t}$ can be expressed by $R_{i t}$, which is the ranking assigned by each respondent to each trait. The empirical formulation is,

$$
\begin{aligned}
R_{i t}^{n}= & \beta_{0}+\beta_{1 t} \text { Trait }_{i t}+\beta_{2} \text { Producer }_{i} \\
& +\beta_{3} \text { Years }_{i}+\beta_{4} \text { Size }_{i}+\beta_{5} \text { NewCultivar }_{i} \\
& +\beta_{6} \text { Cultivar }_{i}+\varepsilon_{i t}
\end{aligned}
$$

where $R_{i t}^{n}$ represents respondent $i$ ranking of trait $t ; n$ is the number of traits in each cluster; Trait $_{i t}$ is the binary variable representing trait $t$ for respondent $i$ (if trait $t$ is selected as most important, then for $R_{i t}=1$, Trait $_{i t}=1$, 0 otherwise; if trait $t$ is selected as second most important, then for $R_{i t}=2$, Trait $_{i t}=1$, 0 otherwise, and so on); Producer ${ }_{i}$ is the binary variable indicating whether the respondent is a producer; Years $_{i}$ is the binary variable indicating whether the number of years of experience in the decision-making process of managing cranberry production is more than 14 (the average number of years in our sample of respondents); Size $_{i}$ is the binary variable indicating whether the operation is $>20.2$ ha. According to extension educators, 50 acres ( $20.2 \mathrm{ha}$ ) is the average minimum operation size for a producer to send his production to a processing facility. For operations less than 50 acres, the production is typically sold by direct marketing; Newcultivar ${ }_{i}$ is the binary variable indicating whether a new cultivar has been planted in the last 5 years; Cultivar ${ }_{i}$ is the binary variable for the cultivar with the largest acreage in the operation, $q(q=$ 'Bergman', 'Ben Lear', 'Crimson Queen', etc.); $\beta_{0}$ is the intercept term, $\beta_{I}-\beta_{6}$ are the coefficients to estimate, and $\varepsilon_{i t}$ is the residual error term that is not captured by the explanatory variables, which is assumed to follow a normal distribution with mean zero and standard deviation $\sigma$.

Because we conducted separate regressions for six trait clusters (fruit quality, disease resistance, arthropod pest resistance, plant stress tolerance, other plant traits, and all trait clusters) and three regions (New Jersey, Wisconsin, and British Columbia), we present results for a total of $18(6 \times 3)$ regressions. The model coefficients were estimated using PROC QLIM in SAS ${ }^{\mathrm{TM}}$ v.9.3 (SAS Institute, Cary, NC).

In each regression analysis, the variable "other trait" was set as the base variable. Hence, the statistical significance of traits should be interpreted as relative to the base variable. Since the most important trait was assigned a rank of 1 , the second most important was assigned 2, and so on; traits with significant negative coefficients were likely to be chosen as more important and traits with significant positive coefficients were likely to be chosen as less important compared with the "other trait" variable in each cluster. The magnitude of the coefficient estimates indicates the relative importance of the variable trait; higher values indicate higher relative importance compared with the base trait. Traits determined not to be statistically significant (that is, not significantly different from the base trait) may still be considered of some importance to producers. Note that we estimated the probability that a trait would be ranked in each category (i.e., most important, second most important, neutral, second least important, and least important), that is, the marginal effects. These estimates are not presented in this manuscript since final interpretation supported coefficient estimates, but are available upon request to authors.

The number of responses obtained from each region was different, with 78 from Wisconsin, 16 from New Jersey, and 22 from British Columbia. Arguably, this difference in the number of responses would have an impact on the value of the coefficient estimates across regions. When presenting the coefficient estimates for all regressions, the McFadden likelihood ratio index is included. This is a measure of goodness-of-fit that depicts the explanatory power of the model.

\section{Results and Discussion}

\section{Summary statistics for respondents by state/province}

Regarding the principal operator, $92 \%$ of respondents were producers, $4 \%$ were representatives from packing houses, 3\% were representatives from a processing facility, $3 \%$ were breeders, and $2 \%$ were nonbreeder researchers. Note that these numbers do not add up to $100 \%$ because some respondents marked more than one category. The average size of cranberry operations was $77.7 \mathrm{ha}$. The largest operations in acreage were located in New Jersey (111.3 ha), followed by Wiscon$\sin$ (75.7 ha), and British Columbia, Canada (62.7 ha). The average operation size in our sample for New Jersey was close to cranberry farm sizes reported by the 2012 Census of Agriculture, at 102.9 ha (U.S. Department of Agriculture, Census of Agriculture, 2012). However, for Wisconsin the average farm size in our sample was bigger compared with the 2012 Census figure, at 34.7 ha (U.S. Department of Agriculture, Census of Agriculture, 2012). The average number of years involved in the decision-making process of cranberry operations was 14 years. Decision makers with the highest number of years of experience were observed in New Jersey (16 years), followed by Wisconsin (14 years), and British Columbia (13 years).

The most predominant cranberry cultivar in production was 'Stevens' (Supplemental Table 1) while 'Mullica Queen' was the most commonly planted cultivar in newly planted cranberry fields (Supplemental Table 2). These results likely reflect historic breeding efforts and trait improvement in cranberry cultivars. 'Stevens' represents one of the first cranberry cultivars, released in 1950 as a result of the first cycle of cranberry genetic improvement efforts and was previously documented as the most widely grown cultivar in the United States (Roper, 2008). 'Mullica Queen' was released in 2007 as part of the second cycle of breeding efforts aiming to improve fruit quality characteristics (e.g., higher anthocyanin content) and productivity (Vorsa and Johnson-Cicalese, 2012). Our survey results suggest that 'Mullica Queen' has been more frequently chosen over 'Stevens' and other cultivars in newly planted cranberry fields, demonstrating that when new cultivars with improved traits are available, producers are willing to change cultivars to increase investment returns.

Across all regions and all seven clusters of breeding traits (Tables 1-6), parameter estimates for the ordered probit model for the operator, operation, and investment in new cultivars variables (e.g., producer, years of experience, size of operation, whether new cultivars were planted, and the cultivars most planted) were not statistically significant, suggesting that differences are mainly explained by geographical regions and not by other factors. 


\section{Fruit and plant trait clusters}

Overall, $53 \%$ of the respondents identified fruit quality as the most important trait cluster to improve in cranberry cultivars. Parameter estimates for the ordered probit model segregating results were different by region (Table 1). In Wisconsin and British Columbia, fruit quality traits were highest in importance among the clusters. In New Jersey, disease resistance was highest in importance, whereas fruit quality traits were second highest. Disease resistance was second highest in importance in Wisconsin, but not significantly different in British Columbia. The high percent of respondents $(>68 \%)$ indicating resistance to fruit rot as the most important trait in New Jersey probably explain why disease resistance ranked higher in this state, where fruit rot in the field can destroy $50 \%$ to $100 \%$ of the fruit if the crop is not protected by fungicides (Oudemans et al., 1998). In other regions such as Wisconsin, Oregon, and British Columbia, fruit rot is more sporadic, and losses are lower than those experienced in the northeast (Oudemans et al., 1998).

Cranberries exhibiting fruit rot damage and deficiencies in fruit size, anthocyanin content, and firmness are being redirected from the SDC to the juice concentrate market, directly affecting the prices received by producers (Nolte, 2015; Serres, 2017; USDA-AMS, 1997, 2016). Currently, the demand for SDC is higher than for juice concentrate, with price premiums paid for the
SDC. Meanwhile, the price for cranberries used for juice concentrate has decreased due to accumulation of fruit that cannot be sold at SDC grades (USDA-ERS, 2017). There is a need to re-equilibrate the balance between the cranberry production destined to each market by improving fruit quality characteristics that meet SDC standards, including fruit rot (Nolte, 2015; Serres, 2017).

Fruit quality traits. In all three states, fruit firmness was the most important quality trait among the list of fruit quality traits presented and compared with the "other" fruit quality category (Table 2). In Wisconsin and British Columbia, fruit size was the second most important trait, but it was not statistically significant in New Jersey. In both New Jersey and Wisconsin, anthocyanin content was selected as more important than the other fruit quality traits in this category, but was selected as second in importance in New Jersey and third in Wisconsin, and not selected as important in British Columbia.

Shelf life, flavor, and sweetness were ranked as the least important traits in all states, compared with the "other" fruit quality category. This probably reflects industry trends that direct a small $(3 \%$ to $5 \%)$ percentage of production to the fresh market (Vorsa and Johnson-Cicalese, 2012), while the majority of producers sell their cranberries to the processing market. Fruit firmness, size, and anthocyanin content contribute to the manufacturing efficiency of SDC products. The SDC market requires fruit with a diameter $>1 / 2$ inches; uniform red color and midrange total anthocyanin (TAcy) of 35-50 mg/100 g fresh weight; round shape; and firm fruit with $>450 \mathrm{~g} / \mathrm{mm}$ with a good flesh integrity (Nolte, 2015; Serres, 2017). Anthocyanin content is traditionally expressed as TAcy, mg of anthocyanin $/ 100 \mathrm{~g}$ fresh fruit and is measured using a spectrophotometer (Vorsa and Johnson-Cicalese, 2012). The observed recent increases in demand for fruit exhibiting these standards could explain producers' desire to improve these quality attributes for new cranberry cultivars.

Fruit firmness is a relatively new quality trait for the cranberry industry (including breeders). Firmness depicts the level of resistance or tolerance to compression forces, a critical characteristic to reduce the risk that the cranberry fruit will break during the SDC processing, which involves multiple handling steps (Nolte, 2015). Cranberry fruit firmness has been evaluated using the compression force method (Forney, 2008) and the mechanical force method (Jamaly et al., 2017) to study how storage conditions and nitrogen affect firmness. Despite the importance of this trait, it is still unknown which and how fruit texture characteristics (crispness, hardness, juiciness, and mealiness), fruit anatomy (skin, flesh, or air pocket) or fruit external appearance (size and shape) are affecting the overall firmness and SDC processing efficiency/yield. In addition, since firmness is a relatively new trait for cranberry breeders,

Table 1. Estimated ordered probit model coefficients for cranberry fruit quality and plant trait clusters and other variables based on a cranberry industry survey conducted in 2017.

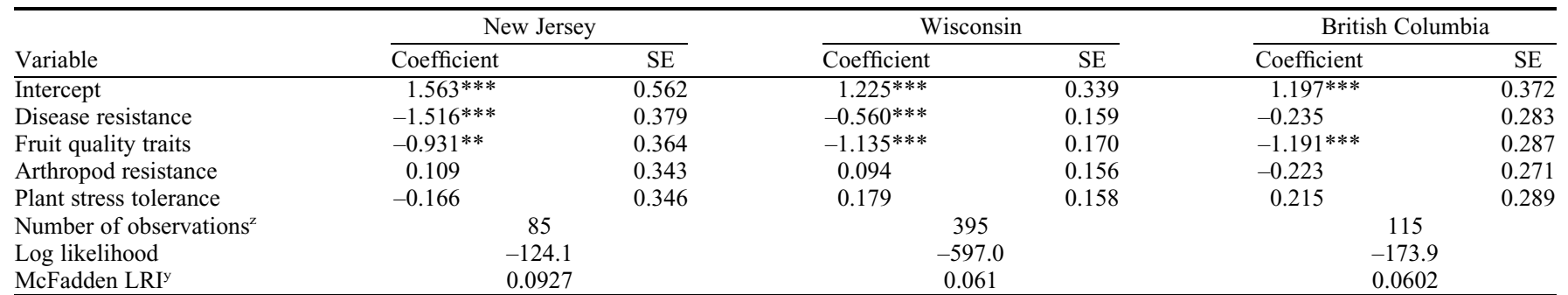

${ }^{\mathrm{z}}$ Each trait ranking generated one observation, thus one respondent generated the number of traits in each cluster or clusters. In this case, each of the respondents generated five observations.

${ }^{y}$ LRI means likelihood ratio index, a statistic that indicates the explanatory power of the model; the higher the number the better.

*, **, ***Significant at $P \leq 0.10,0.05$, or 0.01 , respectively.

Table 2. Estimated ordered probit model coefficients for cranberry fruit quality traits and other variables based on a cranberry industry survey conducted in 2017

\begin{tabular}{|c|c|c|c|c|c|c|}
\hline \multirow[b]{2}{*}{ Variable } & \multicolumn{2}{|c|}{ New Jersey } & \multicolumn{2}{|c|}{ Wisconsin } & \multicolumn{2}{|c|}{ British Columbia } \\
\hline & Coefficient & SE & Coefficient & SE & Coefficient & SE \\
\hline Anthocyanin content & $-0.841 * * *$ & 0.289 & $-0.470 * * *$ & 0.127 & -0.178 & 0.235 \\
\hline Fruit size & 0.243 & 0.274 & $-0.828 * * *$ & 0.131 & $-0.766^{* * *}$ & 0.244 \\
\hline Shelf life & 0.266 & 0.284 & $0.569 * * *$ & 0.130 & 0.210 & 0.235 \\
\hline Flavor & $1.615^{* * *}$ & 0.313 & $0.855^{* * *}$ & 0.132 & $0.751 * * *$ & 0.246 \\
\hline Sweetness & $1.695^{* * *}$ & 0.315 & $0.816^{* * *}$ & 0.130 & $0.823 * * *$ & 0.240 \\
\hline McFadden LRI ${ }^{y}$ & \multicolumn{2}{|c|}{0.1498} & \multicolumn{2}{|c|}{0.0882} & \multicolumn{2}{|c|}{$\begin{array}{l}-289.8 \\
0.0748\end{array}$} \\
\hline
\end{tabular}

${ }^{2}$ Each trait ranking generated one observation, thus one respondent generated the number of traits in each cluster or clusters. In this case, each of the respondents generated seven observations.

${ }^{\mathrm{y}}$ LRI means likelihood ratio index, a statistic that indicates the explanatory power of the model; the higher the number the better.

*, **, ***Significant at $P \leq 0.10,0.05$, or 0.01 , respectively. 
the level of phenotypic variation for firmness in the cranberry germplasm has not yet been explored.

Developing high precision and costeffective strategies to evaluate traits such as fruit size and anthocyanin content is important since many factors, including environmental conditions and management practices (Roper, 2006), can affect their expression. Also, cranberry exhibits useful genetic variation for these traits (Vorsa and JohnsonCicalese, 2012), suggesting opportunities to identify associated molecular markers that can be used to improve fruit characteristics important for the industry (Daverdin et al., 2017; Georgi et al., 2013; Schlautman et al., 2015).

Traditionally, cranberry fruit size has been evaluated by approximation of average fruit weight (Diaz-Garcia et al., 2016), and anthocyanin content (qualitative and quantitative) has been evaluated through highperformance liquid chromatography (HPLC) (Vorsa and Johnson-Cicalese, 2012). However, these methods are time-consuming, expensive, and cannot measure how uniform the anthocyanin (color) is distributed on the fruit epidermis. Furthermore, fruit size and anthocyanin content are negatively correlated (Vorsa and Welker, 1985), increasing the need to further understand how these correlations affect cranberry fruit utilization and price. Recently, high-throughput and accurate methods based on imaging analysis were developed to evaluate several cranberry fruit characteristics including size, color, and shape (Diaz Garcia et al., 2016). Integrating these methods into large-scale studies represents an opportunity for extensive characterization of plant phenotypes, by studying their genetic makeup and their interaction with the environment more effectively.

Disease and arthropod pest resistance traits. In all regions, resistance to fruit rot was the highest in importance among the list of diseases presented and compared with the "other" disease category (Table 3 ). In general, field fruit rot is of economic concern in most areas of cranberry production in the United States and Canada (Polashock et al., 2009). In Massachusetts and New Jersey, producers need to apply broad-spectrum fungicides four to six times per year to nearly all cranberry acreage (Oudemans et al., 1998). In Wisconsin, Oregon, Washington, and southern Canada, where the incidence of the disease is low, fungicides are needed only in specific areas or years (McManus et al., 2003). Because of the near-zero tolerance for fruit rot in the SDC market, losses associated with this disease are due to the rejection or downgrading of affected fruit loads (Nolte, 2015).

In 2015, during the Northeastern IPM cranberry fruit rot working group meeting, scientists and industry representatives identified studying the impact of fruit rot on fruit firmness as the top research priority need (Oudemans and Rojas, 2015). Sources of resistance to fruit rot have been identified in cranberry germplasm, and the trait is being introgressed into genetic backgrounds with higher yields, as well as good berry size and color (Johnson-Cicalese et al., 2015). Recently, molecular markers associated with fruit rot resistance were identified (Daverdin et al., 2017) opening the opportunity to develop and implement a MAS strategy to accelerate the development of new cranberry cultivars resistant to fruit rot.

Besides fruit rot, the rest of the disease resistance traits included in the list were assigned different rankings of importance according to the region, probably due to the different environmental conditions which can influence the prevalence of specific types of diseases and potential disease vectors (Colhoun, 1973). For example, in New Jersey, fairy ring was the second most important disease resistance trait, but not in Wisconsin or British Columbia, where it was listed among the least important problems.
Similarly, results for arthropod pest resistance traits differed across regions (Table 4). Among the list of arthropod pests presented and compared with the "other" arthropod pest category, blunt-nosed leafhopper was the most important pest resistance trait in New Jersey, cranberry fruit-worm in Wisconsin, and cranberry tip-worm in British Columbia. Higher variation for pest and arthropod pest resistance responses were expected, since differences in environmental conditions in different production regions impact the type of arthropod pests and pest pressures (DeLucia et al., 2012).

Abiotic stress traits. Differences across regions in the ranking of abiotic stress traits were observed (Table 5). In New Jersey, tolerance to heat stress was selected as the most important abiotic stress, whereas in Wisconsin and British Columbia tolerance to fall frost and spring frost were selected as the most important traits, among the list of abiotic stress traits presented and compared with the "other" abiotic stress category. The different environmental conditions of the geographic locations represented in the survey combined with cranberry physiological characteristics explain these results. Optimum growth for cranberry occurs when the temperature is between $16{ }^{\circ} \mathrm{C}$ and $30{ }^{\circ} \mathrm{C}$, and excessive heat $\left(>33^{\circ} \mathrm{C}\right)$ during summer months has been associated with poor yields (Roper, 2006). Of all the cranberry production areas in North America, conditions in New Jersey expose the cranberry plants to the highest heat stress (Roper, 2006). Indeed, to mitigate heat stress in this region, the use of irrigation systems is recommended for cooling (Caron et al., 2017). In contrast, the period of freezing temperatures and overall lower temperatures that cranberry plants are exposed to in Wisconsin and British Columbia explain why frost protection is a concern for producers in these regions. However, standardized methods to evaluate tolerance to abiotic stresses and the identification of genetic mechanisms

Table 3. Estimated ordered probit model coefficients for cranberry disease resistance traits and other variables based on a cranberry industry survey conducted in 2017.

\begin{tabular}{|c|c|c|c|c|c|c|}
\hline \multirow[b]{2}{*}{ Variable } & \multicolumn{2}{|c|}{ New Jersey } & \multicolumn{2}{|c|}{ Wisconsin } & \multicolumn{2}{|c|}{ British Columbia } \\
\hline & Coefficient & SE & Coefficient & $\mathrm{SE}$ & Coefficient & SE \\
\hline Field fruit rot & $-1.978 * * *$ & 0.273 & $-1.653 * * *$ & 0.121 & $-1.361 * * *$ & 0.208 \\
\hline Phytophthora & $-0.772 * * *$ & 0.234 & 0.228 & 0.144 & -0.127 & 0.257 \\
\hline False blossom & $-0.627^{*}$ & 0.361 & $0.527 * * *$ & 0.151 & 0.296 & 0.301 \\
\hline Storage rots & -0.085 & 0.281 & $0.445 * * *$ & 0.119 & -0.364 & 0.232 \\
\hline Leaf spots & $0.897 * * *$ & 0.263 & $0.675^{* * *}$ & 0.126 & 0.399 & 0.246 \\
\hline Bitter rot & $1.396 * * *$ & 0.276 & -0.125 & 0.119 & $1.105 * * *$ & 0.263 \\
\hline Cottonball & $1.600 * * *$ & 0.254 & $-0.389 * * *$ & 0.118 & 0.419 & 0.296 \\
\hline Nematodes & $1.624 * * *$ & 0.362 & $1.071 * * *$ & 0.124 & 0.386 & 0.248 \\
\hline Number of observations $\mathrm{z}^{\mathrm{z}}$ & \multirow{2}{*}{\multicolumn{2}{|c|}{221}} & \multicolumn{2}{|c|}{1027} & \multicolumn{2}{|c|}{299} \\
\hline Log Likelihood & & -494.7 & \multicolumn{2}{|c|}{$-2,420.0$} & \multicolumn{2}{|c|}{-717.9} \\
\hline McFadden LRI ${ }^{y}$ & \multicolumn{2}{|c|}{0.1272} & \multicolumn{2}{|c|}{0.0814} & \multicolumn{2}{|c|}{0.0639} \\
\hline
\end{tabular}

${ }^{2}$ Each trait ranking generated one observation, thus one respondent generated the number of traits in each cluster or clusters. In this case, each of the respondents generated 13 observations.

${ }^{\mathrm{y}}$ LRI means likelihood ratio index, a statistic that indicates the explanatory power of the model; the higher the number the better.

*, **, ***Significant at $P \leq 0.10,0.05$, or 0.01 , respectively. 
controlling these traits, which could assist breeding programs, are still not available.

Other plant traits. In all three regions, improved plant yield and flowering/fruit set were selected as the most and second most important other plant trait (Table 6). Yield is a complex trait affected by genetic and environmental factors, and has historically been a major focus of the cranberry breeding programs (Daverdin et al., 2017; Georgi et al., 2013; Roper, 2006; Schlautman et al., 2015; Vorsa and Johnson-Cicalese, 2012). Yield is currently estimated by harvesting and weighing all the fruit from square foot samples. This method is not time effective and does not work well for juvenile plantings or small plots due to increased standard errors. In addition, several plant characteris- tics (e.g., upright density, inflorescence bud set, flower number/upright, gametic fertility) affect fruit yield, including fruit set, which has been identified as a key characteristic to target in breeding programs to improve yield performance (Vorsa and Johnson-Cicalese, 2012), and probably explains why fruit set ranked as the second most important trait. Despite the complexity of this trait, genetic

Table 4. Estimated ordered probit model coefficients for cranberry arthropod pest resistance traits and other variables based on a cranberry industry survey conducted in 2017.

\begin{tabular}{|c|c|c|c|c|c|c|}
\hline \multirow[b]{2}{*}{ Variable } & \multicolumn{2}{|c|}{ New Jersey } & \multicolumn{2}{|c|}{ Wisconsin } & \multicolumn{2}{|c|}{ British Columbia } \\
\hline & $\overline{\text { Coefficient }}$ & $\mathrm{SE}$ & $\overline{\text { Coefficient }}$ & $\mathrm{SE}$ & Coefficient & $\mathrm{SE}$ \\
\hline Blunt-nosed leafhoppers & $-1.677 * * *$ & 0.277 & $1.366 * * *$ & 0.151 & $1.393 * * *$ & 0.269 \\
\hline Blackheaded fireworm & $-1.168 * * *$ & 0.261 & $-0.845^{* * *}$ & 0.114 & $-0.870 * * *$ & 0.222 \\
\hline Cranberry fruitworm & $-0.989 * * *$ & 0.320 & $-2.071 * * *$ & 0.122 & $-0.707 * *$ & 0.293 \\
\hline Sparganothis fruitworm & $-0.857 * * *$ & 0.262 & $-1.405^{* * *}$ & 0.117 & -0.345 & 0.300 \\
\hline Grub & -0.370 & 0.283 & $1.041 * * *$ & 0.164 & $1.644 * * *$ & 0.416 \\
\hline Cranberry weevil & 0.479 & 0.337 & $1.001 * * *$ & 0.177 & 0.091 & 0.350 \\
\hline Flea beetle & $0.687^{* *}$ & 0.284 & $-0.690^{* * *}$ & 0.116 & $1.142 * * *$ & 0.330 \\
\hline Girdler & $0.797 * *$ & 0.335 & $-0.463 *$ & 0.261 & $-1.095 * * *$ & 0.216 \\
\hline Scale insects & $1.413 * * *$ & 0.268 & $1.354 * * *$ & 0.134 & -0.167 & 0.232 \\
\hline Root weevil & $1.533 * * *$ & 0.340 & $0.870^{* * *}$ & 0.147 & -0.009 & 0.258 \\
\hline Thrips & $1.804 * * *$ & 0.295 & $1.246^{* * *}$ & 0.128 & $0.580 * *$ & 0.262 \\
\hline Toadbugs & -0.141 & 0.285 & $1.860 * * *$ & 0.123 & $1.299 * * *$ & 0.246 \\
\hline
\end{tabular}

${ }^{\mathrm{z}}$ Each trait ranking generated one observation, thus one respondent generated the number of traits in each cluster or clusters. In this case, each of the respondents generated 16 observations.

${ }^{y}$ LRI means likelihood ratio index, a statistic that indicates the explanatory power of the model; the higher the number the better.

$*, * *, * * *$ Significant at $P \leq 0.10,0.05$, or 0.01 , respectively.

Table 5. Estimated ordered probit model coefficients for cranberry abiotic stress tolerance traits and other variables based on a cranberry industry survey conducted in 2017.

\begin{tabular}{|c|c|c|c|c|c|c|}
\hline \multirow[b]{2}{*}{ Variable } & \multicolumn{2}{|c|}{ New Jersey } & \multicolumn{2}{|c|}{ Wisconsin } & \multicolumn{2}{|c|}{ British Columbia } \\
\hline & Coefficient & SE & Coefficient & SE & Coefficient & SE \\
\hline Heat stress & $-1.397 * * *$ & 0.410 & -0.006 & 0.143 & -0.370 & 0.24 \\
\hline Yellow vine & $1.835^{* * *}$ & 0.406 & $0.808 * * *$ & 0.148 & $1.090 * * *$ & 0.26 \\
\hline Midwinter cold hardiness & $1.974 * * *$ & 0.413 & $0.708 * * *$ & 0.146 & $0.545^{* *}$ & 0.25 \\
\hline Number of observations ${ }^{z}$ & \multicolumn{2}{|c|}{$\begin{array}{c}102 \\
-1411\end{array}$} & \multicolumn{2}{|c|}{474} & \multicolumn{2}{|c|}{138} \\
\hline
\end{tabular}

${ }^{\mathrm{z}}$ Each trait ranking generated one observation, thus one respondent generated the number of traits in each cluster or clusters. In this case, each of the respondents generated six observations.

${ }^{y}$ LRI means likelihood ratio index, a statistic that indicates the explanatory power of the model; the higher the number the better.

$*, * *, * *$ Significant at $P \leq 0.10,0.05$, or 0.01 , respectively.

Table 6. Estimated ordered probit model coefficients of other cranberry plant traits and other variables based on a cranberry industry survey conducted in 2017.

\begin{tabular}{|c|c|c|c|c|c|c|}
\hline \multirow[b]{2}{*}{ Variable } & \multicolumn{2}{|c|}{ New Jersey } & \multicolumn{2}{|c|}{ Wisconsin } & \multicolumn{2}{|c|}{ British Columbia } \\
\hline & $\overline{\text { Coefficient }}$ & $\mathrm{SE}$ & $\overline{\text { Coefficient }}$ & $\mathrm{SE}$ & Coefficient & $\mathrm{SE}$ \\
\hline Yield & $-2.502 * * *$ & 0.453 & $-1.649 * * *$ & 0.177 & $-2.235 * * *$ & 0.37 \\
\hline Runnering habit & $0.731^{* *}$ & 0.360 & $0.999 * * *$ & 0.161 & $0.849 * * *$ & $0.31^{\prime}$ \\
\hline Number of observations $\mathrm{z}^{\mathrm{z}}$ & \multirow{2}{*}{\multicolumn{2}{|c|}{$\begin{array}{c}85 \\
-1050\end{array}$}} & \multicolumn{2}{|c|}{395} & \multicolumn{2}{|c|}{115} \\
\hline Log likelihood & & & \multicolumn{2}{|c|}{$\begin{array}{l}-527.6 \\
01701\end{array}$} & \multicolumn{2}{|c|}{-131.8} \\
\hline
\end{tabular}

${ }^{2}$ Each trait ranking generated one observation, thus one respondent generated the number of traits in each cluster or clusters. In this case, each of the respondents generated five observations.

${ }^{\text {y }}$ LRI means likelihood ratio index, a statistic that indicates the explanatory power of the model; the higher the number the better.

*, **, ***Significant at $P \leq 0.10,0.05$, or 0.01 , respectively. 
gains for increased yield and consistent yearto-year yield have been realized in cranberry since the first cycle of hybrids were released back in 1950 (Vorsa and Johnson-Cicalese, 2012). Recently, molecular markers have been associated to fruit rot resistance and other related traits, including sound fruit yield, which represent the amount of fruit harvested that are nonsoft and nondiseased by fruit rot (Daverdin et al., 2017). Besides fruit rot resistance, the phenotype sound fruit yield may also be indicative of fruit firmness and can possibly be used in the breeding programs to select superior genotypes that produce fruit with improved firmness and no disease (by fruit rot). These two traits/parameters are both used to sort fruit that can and cannot be used for SDC production. To ensure profitable returns and the long-term sustainability of the cranberry industry, time and cost effective strategies and methods to estimate SDC usable yield, which takes into account quality standards used by the processing industry, should be established.

\section{Summary and Conclusions}

This study is the first report of the most impactful cranberry fruit and plant traits for the industry in major growing areas in the United States and Canada. The study determined the importance of a selected number of plant and fruit traits to assert which should be included in new improved cultivars to warrant success in the market place. The survey that was conducted in New Jersey, Wisconsin, and British Columbia (Canada) predominantly targeted producers responsible for the decision making in their business operation. We grouped the trait responses in five clusters: fruit quality, disease resistance, arthropod pest resistance, plant stress tolerance, and other plant traits. Industry responses were mixed and varied across regions. In Wisconsin and British Columbia fruit quality was the most important trait cluster, whereas in New Jersey it was disease resistance. Among fruit quality traits, fruit firmness, size, and anthocyanin content were ranked the most important due to the emergence and higher profitability of the SDC market. While high-throughput methods to measure cranberry fruit size and color have been developed, they need to be implemented on a large scale. Methods to evaluate fruit firmness relevant to SDC production also need to be developed. The different environmental conditions amongst regions influenced the differences observed in the ranking of traits which were considered important.

Results from this study will aid academia, government, and industry interested in enhancing the economic profitability of the cranberry industry in North America. The outcomes provided cues where investment in research and development should focus to lessen the challenges affecting this industry.

\section{Literature Cited}

Alpuerto, V.E., G.W. Norton, J. Alwang, and A.M. Ismail. 2009. Economic impact analysis of marker-assisted breeding for tolerance to salinity and phosphorous deficiency in rice. Rev. Agr. Econ. 31:779-792.

Alston, J.M., J. Medelin-Azuara, and T.L. Saitone. 2014. Economic impact of the North American cranberry industry. 19 Mar. 2018. <http://www. uscranberries.com/Images/News/GeneralFolder/ EIReport20140814.pdf $>$.

Caron, J., V. Pelletier, J. Gallichand, S. Gumiere, and S. Pepin. 2017. Guidelines of irrigation and drainage management strategies to enhance cranberry production and optimize water use in North America. Can. J. Soil Sci. 97:82-91.

CMC. 2016. Cranberry Marketing Committee, Cranberry data and report 2016. 27 Apr. 2018. <http:// www.uscranberries.com/TheCranberryStory/ ReportingSelfServiceCenter/>.

CMC. 2017. Cranberry Marketing Committee, Cranberry data and report 2017.27 Apr. 2018. <http:// www.uscranberries.com/TheCranberryStory/ ReportingSelfServiceCenter/>.

Colhoun, J. 1973. Effects of environmental factors on plants disease. Annu. Rev. Phytopathol. 11: 343-364.

Covarrubias-Pazaran, G., L. Diaz-Garcia, B. Schlautman, J. Deutsch, W. Salazar, M. Hernandez-Ochoa, E. Grygleski, S. Steffan, M. Iorizzo, J. Polashock, N. Vorsa, and J. Zalapa. 2016. Exploiting genotyping by sequencing to characterize the genomic structure of an understudied species, the American cranberry. BMC Genomics 17(451). doi: 10.1186/s12864-0162802-3.

Daverdin, G., J. Johnson-Cicalese, J. Zalapa, N Vorsa, and J.J. Polashick. 2017. Identification and mapping of fruit rot resistance QTL in American cranberry using GBS. Mol. Breeding 37(3). doi: 10.1007/s11032-017-0639-3.

Davis, C.G. and J.M. Gillespie. 2004. What role does specialization play in farm size in the United States hog industry? Southern Agricultural Economics Association Annual Meeting. 14-18 Feb. 2004, Tulsa, OK.

DeLucia, H.E., P.D. Nabity, J.A. Zavala, and M.R. Berenbaum. 2012. Climate change: Resetting plant-insect interactions. J. Plant Physiol. 160:1677-1685.

Diaz-Garcia, L., G. Covarrubias-Pazaran, B. Schlautman, and J. Zalapa. 2016. GiNA, an efficient and high-throughput software for horticultural phenotyping. PLoS One 11(8): E0160439.

FAOSTAT. 2016. Cranberry statistics. FAOSTAT Database. Rome, Italy: FAO. 28 Mar. 2018 $<$ http://www.fao.org/faostat/en/\#data $>$.

Farm Credit East (FCE). 2015. Massachusetts cranberry cost of production study. 2 Aug. 2018. $<$ https://www.farmcrediteast.com/knowledge-exchange/Reports/massachusetts-cranberry-cost-ofproduction-study-2012-2014-crop-years $>$.

Forney, C.F. and W. Kalt. 2011. Blueberry and cranberry, p. 51-73. In: A.T. Leon (ed.) Health-promoting properties of fruit and vegetables. CABI, Wallingford, UK.

Forney, C. 2008. Optimizing the storage temperature and humidity for fresh cranberries: A reassessment of chilling sensitivity. HortScience 43:439-446.

Gallardo, R.K., Q. Zhang, M. Dossett, J.J. Polashock, C. Rodriguez-Saona, N. Vorsa, P.P. Edger, H. Ashrafi, E. Babiker, C.E. Finn, and M. Iorizzo. 2018. Breeding trait priorities of the blueberry industry in the United States and Canada. HortScience 53:1021-1028.

Gallardo, R.K., D. Nguyen, V. McCracken, C. Yue, J. Luby, and J. McFerson. 2012. An investigation of trait prioritization in rosaceous fruit breeding programs. HortScience 47:771-776.
Georgi, L., J. Johnson-Cicalese, J. Honig, S.P. Das, V.D. Rajah, D. Bhattacharya, N. Bassil, L.J. Rowland, J.J. Polashock, and M. Vorsa. 2013. The first genetic map of the American cranberry: Exploration of synteny conservation and quantitative trait loci. Theor. Appl. Genet. 126:673-692.

Greene, W.H. and D.A. Hensher. 2008. Modeling ordered choices: A primer and recent developments. Working paper, New York University. 29 Mar. $2018<$ https://papers.ssrn.com/sol3/papers. cfm?abstract_id=1213093>.

Huang, W., Y. Zhu, C. Li, Z. Sui, and W. Min. 2016. Effect of blueberry anthocyanins malvidin and glycosides on the antioxidant properties in endothelial cells. Oxid. Med. Cell. Longev. 1591803:1-10.

Jamaly, R., S. Marchand, S.É. Perent, S.J. Gumiere, J.-P. Deland, and L.É. Parent. 2017. Impact of fertilization on the firmness of cranberry (Vaccinium macrocarpon AIT.). North American Cranberry Researcher and Extension Worker Conference. Aug. 27-30, 2017, Plymouth, MA.

Johnson-Cicalese, J., N. Vorsa, J.J. Polashock, and D.L. Ward. 2015. Heritability of fruit rot resistance in American cranberry. J. Amer. Soc. Hort. Sci. 140:233-242.

Lancaster, K.J. 1966. A new approach to consumer behavior theory. J. Polit. Econ. 74:132-157.

Luby, J.J. and D.V. Shaw. 2001. Does markerassisted selection make dollars and sense in a fruit breeding program? HortScience 36:872879.

McManus, P.S., R.W. Caldwell, R.P. Voland, and V.M. Best. 2003. Evaluation of sampling strategies for determining incidence of cranberry fruit rot and fruit rot fungi. Plant Dis. 87:585590.

Nolte, D. 2015. Industry trends and research implications. North American Cranberry Researcher and Extension Worker Conference. Aug. 24-25, 2015. Brandon, OR. 1 Mar. 2018 $<\mathrm{http}$ ://www.oregoncranberrygrowers.com/sites/ default/files/d.nolte_industry_trends_and_ research_implications_0.pdf $>$.

Oudemans, P.V. and E.S. Rojas. 2015. Northeastern IPM Cranberry Fruit Rot Working Group meeting summary. 15 Jan. 2018. <http://www. northeastipm.org/neipm/assets/File/CranberryFruit-Rot-Working-Group-Meeting-Report-Aug2015.pdf>

Oudemans, P.V., F.L. Caruso, and A.W. Stretch. 1998. Cranberry fruit rot in the Northeast: A complex disease. Plant Dis. 82:1176-1184.

Polashock, J.J., F.L. Caruso, P.V. Oudemans, P.S McManus, and J.A. Crouch. 2009. The North American cranberry fruit rot fungal community: A systematic overview using morphological and phylogenetic affinities. Plant Pathol. 58:1116-1127.

Roper, T. 2008. Cranberry production in Wisconsin. 15 Jan. 2018. <http://www.wiscran.org/ user_image/pdf_files/CranProduction08.pdf $>$.

Roper, T. 2006. The physiology of cranberry yield. Cranberry Station Fact Sheets. 16. 1 Mar. 2018. <https://scholarworks.umass.edu/ cgi/viewcontent.cgi? article $=1015 \&$ context $=$ cranberry_factsheets $>$.

Schlautman, B., G. Covarrubias-Pazaran, L. DiazGarcia, J. Johnson-Cicalese, M. Iorrizo, L. Rodriguez-Bonilla, T. Bougie, T. Bougie, E. Wiesman, S. Steffan, J. Polashock, N. Vorsa, and J. Zalapa. 2015. Development of a highdensity cranberry SSR linkage map for comparative genetic analysis and trait detection. Mol. Breed. 35:177. doi: 10.1007/s11032-0150367-5. 
Schlautman, B., G. Covarrubias-Pazaran, L. DiazGarcia, M. Iorizzo, J. Polashock, E. Grygleski, N. Vorsa, and J. Zalapa. 2017. Construction of a high-density American cranberry (Vaccinium macrocarpon Ait.) composite map using genotyping-by-sequencing for multi-pedigree linkage mapping. G3: Genes, Genomes. Genetics 7:1177-1189.

Serres, R. 2017. Fruit quality and trend in the cranberry industry. BC Cranberry Congress, 7 Feb. 2017. 9 Apr. 2018. <http://www.bccranberries.com/pdfs/ 2017 cranberry-congress $/ 10 \% 20$ Fruit $\% 20$ Quality $\% 20$ and $\% 20$ Trends $\% 20$ in $\% 20$ the $\% 20$ Cranberry $\% 20$ Industry.pdf $>$.

Song, Y., L. Huang, and Y. Jianfeng. 2016. Effects of blueberry anthocyanins on retinal oxidative stress and inflammation in diabetes through Nrf2/HO-1 signaling. J. Neuroimmunol. 301:1-6.

United States Department of Agriculture, Agricultural Marketing Service (USDA-AMS). 1997. United States Standards for Grades of Fresh Cranberries. United States Dept. Agr., Washington, D.C. 1 Mar. 2018. <https://www.ams. usda.gov/sites/default/files/media/Cranberry_ Standard\%5B1\%5D.pdf>.

United States Department of Agriculture, Agricultural Marketing Service (USDA-AMS). 2016.
United States Standards for Grades of Fresh Cranberries for Processing. United States Dept. Agr., Washington, D.C. 1 Mar. 2018. <https:// www.ams.usda.gov/sites/default/files/media/ FreshCranberriesforProcessingStandard.pdf $>$.

United States Department of Agriculture. Census of Agriculture. 2012. 7 July 2018. <https:// www.agcensus.usda.gov/Publications/2012/>.

United States Department of Agriculture, Economic Research Service (USDA-ERS). 2017. Fruit and tree nuts outlook. 29 Sept. 2017. 7 Mar. 2018. <https://www.ers.usda.gov/webdocs/ publications $/ 85287 /$ fts-365.pdf>.

United States Department of Agriculture, National Agriculture Statistics Service. (USDA NASS). 2017a. National statistics for cranberry. 1 Mar. 2018. <http://usda.mannlib.cornell.edu/usda/ current/Cran/Cran-08-10-2017.pdf \$.

United States Department of Agriculture, National Agriculture Statistics Service. (USDA NASS). 2017b. National statistics for cranberry. 1 Mar. 2018. <http://usda.mannlib.cornell.edu/ usda/current/NoncFruiNu/NoncFruiNu-06-272017.pdf>.

United States Food and Drug Administration (U.S. FDA). 2016. Food labeling: Revision of the nutrition and supplement facts labels-rules and regulations. 13 Mar. 2018. <https://www.
gpo.gov/fdsys/pkg/FR-2016-05-27/pdf/201611867.pdf>.

United States Food and Drug Administration (U.S. FDA). 2016. The declaration of added sugars on honey, maple syrup, and certain cranberry products: Guidance for industry. 26 July 2018. <https://www.fda.gov/downloads/ food/guidanceregulation/guidancedocuments regulatoryinformation/ucm596469.pdf>.

Vorsa, N. and J. Johnson-Cicalese. 2012. American cranberry. In: M.L. Badenes and D.H. Byrne (eds.). Fruit breeding: handbook of plant breeding. Springer, New York.

Vorsa, N. and W.V. Welker. 1985. Relationship between fruit size and extractable anthocyanin content in cranberry. HortScience 20:402403.

Yang, H., C. Li, H.-M. Lam, J. Clements, G. Yan, and S. Zhao. 2015. Sequencing consolidates molecular markers with plant breeding practice. Theor. Appl. Genet. 128:779-795.

Yue, C., R.K. Gallardo, J. Luby, A. Rihn, J.R. McFerson, V. McCracken, D. Bedford, S. Brown, K. Evans, C. Weebadde, A. Sebolt, and A.F. Iezzoni. 2013. An investigation of United States apple producers' trait prioritizationEvidence from audience surveys. HortScience 48:1378-1384. 
Supplemental Table 1. Number of respondents indicating which cultivars represented the largest acreage in their operation and which cultivars were planted in the last 5 years with the largest acreage based on a cranberry industry survey conducted in 2016 and 2017.

\begin{tabular}{|c|c|c|c|c|c|c|c|}
\hline & \multicolumn{7}{|c|}{ Current varieties being planted with the largest acreage, with number of responses } \\
\hline & Stevens & Early Black & Bergman & Ben Lear & Mullica Queen & Pilgrim & Sundance \\
\hline New Jersey & 8 & 8 & 0 & 0 & 0 & 0 & 0 \\
\hline Wisconsin & 62 & 0 & 0 & 2 & 1 & 1 & 2 \\
\hline British Columbia & 15 & 0 & 2 & 0 & 1 & 1 & 0 \\
\hline \multirow[t]{3}{*}{ Total } & 85 & 8 & 2 & 2 & 2 & 2 & 2 \\
\hline & \multicolumn{7}{|c|}{ Newly planted varieties with the largest acreage, with number of responses } \\
\hline & Stevens & Mullica Queen & Sundance & & & & \\
\hline New Jersey & 0 & 7 & 0 & & & & \\
\hline Wisconsin & 11 & 20 & 7 & & & & \\
\hline British Columbia & 2 & 5 & 0 & & & & \\
\hline Total & 13 & 32 & 7 & & & & \\
\hline
\end{tabular}

Supplemental Table 2. Replanting distribution of current cranberry cultivars with new cranberry cultivars based on an industry survey conducted in 2016 and 2017.

\begin{tabular}{lccc}
\hline & \multicolumn{3}{c}{ Newly planted cultivar } \\
\cline { 2 - 4 } Current cultivar & Stevens & Mullica Queen & Sundance \\
\hline Stevens $(\mathrm{N}=85)$ & 13 & 32 & 7 \\
Early Black $(\mathrm{N}=8)$ & 0 & 38 & 0 \\
Ben Lear $(\mathrm{N}=2)$ & 50 & 0 & 0 \\
Mullica Queen $(\mathrm{N}=2)$ & 0 & 100 & 0 \\
Pilgrim $(\mathrm{N}=2)$ & 0 & 50 & 0 \\
Sundance $(\mathrm{N}=2)$ & 50 & 0 & 50 \\
\hline
\end{tabular}

